\title{
KONSTELASI BAHASA JAWA MODERN \\ DALAM PAGELARAN WAYANG KULIT PURWA (KAJIAN SOSIOLINGUISTIK)
}

\author{
Udjang Pr. M. Basir \\ Jurusan Pendidikan Bahasa Daerah \\ Fakultas Bahasa dan Seni, Universitas Negeri Surabaya
}

\begin{abstract}
The shadow puppet performance as part of the Javanese folk arts reflects the society's life attitude and philosophy. This art is not only a performance, but it is also guidance consisting of traditional values and didactic philosophy that the society can employ. Language is a medium of communication to present the values and essence of the story in a shadow puppet performance and has an important and strategic function. Through language, shadow puppet characters are made alive by the puppeteer. This study investigates language variants in the shadow puppet performance. There are six types, namely kasar, ngoko, madya, krama, bagongan and renggabasa. Renggabasa is used in sulukan, janturan, antawecana, panyandra, and sasmita. The data reveal that the elaboration shows the growth of the Javanese levels more comprehensively.
\end{abstract}

Keywords: shadow puppet performance, guidance, didactic philosophy

\section{A. PENDAHULUAN}

Wayang purwa sebagai bagian dari budaya Jawa merupakan prototipe kesenian tradisional yang merakyat dan tua usianya. Sekalipun bertema sentral epos India, yaitu Mahabharata dan Ramayana, sentuhan kreativitas penyadurnya (Mpu Wiyasa dan Empu Walmiki) membuat kesenian wayang purwa (wayang kulit) bagi masyarakat Jawa tidak dirasakan lagi sebagai budaya import, bahkan secara filosofis menggambarkan potret budaya Jawa yang paling komprehensif. Mulai dari perangkat kelengkapan fisik dalam pertunjukan, seperti: tuwuhan 'tumbuhan', sajen 'sesaji', gamelan 'musik', kelir 'bentangan kain putih', gedebog 'pohon pisang', blencong 'lampu', boneka wayang, dalang, sindhen 'penyanyi pengiring', dan wiyaga 'penabuh gamelan', merupakan refleksi dari sikap hidup orang Jawa pada umumnya.

Karakter tokoh, roh ceritra dan tempat pun telah disetting sedemikian rupa sehingga citra aspek kejawaannya kental. Misalnya, pelukisan (janturan) tentang profil kerajaan
Astina Pura saat jejeran raja Duryudana dan ponggawanya: ... Nagari kang apanjang punjung, pasir wukir loh jinawi, gemah ripah karta raharja (gambaran keadaan tanah di Jawa yang subur makmur). Demikian pula gambaran karakteristik negara: ... Nagari ngunggkuraken pagunungan, ngiringaken benawi, nengenaken pasabinan, ngayunaken bandaran agung (gambaran keberadaan keraton Jawa (Yogyakarta dan Surakarta). Aspek kejawaannya juga dapat dirasakan, betapa pemaparan narasi ceritra pertunjukan wayang paling tepat disampaikan dengan menggunakan bahasa Jawa, bukan bahasa yang lain. Usaha pemakaian bahasa Indonesia dan bahasa Inggris dalam rangka globalisasi, tidak dapat menandingi aspek ke-adiluhungan wayang sebagai karya budaya Jawa.

\section{B. TINGKAT TUTUR DALAM BAHASA JAWA \\ Pada era globalisasi ini, proses} komunikasi seseorang tidaklah steril dari berbagai pengaruh bahasa lain maupun ragam- 
ragam tertentu yang dikuasai. Hal itu pula yang menjadi konsekuensi berlakunya hukum kedwibahasaan yang umumnya dimiliki manusia modern yang hidup di era globalisasi ini. Proses komunikasi yang berlangsung hampir tidak dapat dibatasi dengan sekat-sekat satu bahasa tertentu (ekabahasa), baik dalam percakapan formal maupun informal, apalagi jika sudah bersentuhan dengan hal-hal yang bersifat ilmu dan teknologi. Namun demikian perbedaan-perbedaan itu biasanya masih saling difahami sebab secara karakteristik komunikasi biasanya berkembang di seputar satu bahasa atau satu rumpun bahasa meskipun kadangkala terinterferensi unsur bahasa lain terjadi secara sporadis. Dengan demikian unsur varian dalam proses komunikasi pada umumnya hanya berkembang di seputar perbedaan yang bersifat idiolek, dialek, sosiolek, dan register (Fishman, 1972; Basir, 2002).

Rangkaian perbedaan yang sistemik dan mereferensikan suatu perilaku bahasa yang menjadi standar dalam tata pergaulan di masyarakat umum, dalam budaya Jawa dikenal dengan istilah unggah-ungguh basa atau tingkat tutur. Unggah-ungguh sendiri dapat diartikan sebagai adat sopan-santun dalam pergaulan, etika pergaulan, tata susila, atau tatakrama (Adisumarto, 1991:1-2).

Unggah-ungguh bahasa Jawa dianggap sebagai etiket berbahasa (language etiquette) yang menempatkan kaidah sopan santun sebagai tolok ukurnya. Apakah perilaku berbahasa seseorang dipandang halus atau kasar, hormat atau tidak hormat, sopan atau tidak sopan, rujukannya adalah pada kaidah etika yang berlaku pada suatu bahasa. Peristiwa berbahasa (speech event) dan tindak berbahasa (speech act) yang dilakukan seseorang itu bebas sifatnya. Namun secara pragmatik terikat aturan sosial karena praktek komunikasi menyangkut kepentingan banyak pihak (konvensi). Sebagaimana umum dijumpai dalam buku-buku Paramasatra (tatabahasa Jawa), pola pembahasan sistem unggahungguh bahasa Jawa sampai pertengahan abad 20 relatif sama. Hampir semua sistem unggahungguh yang berlaku saat itu dan bahkan sampai sekarang, mengikuti konsep pembagian Padmasoesastra pada buku Serat Tatacara (1893). Khusus pembagian sistem unggahungguh bahasa Jawa, baik Padmasoesastra (1893), Karti Basa (1946), Poerwadarminta (1953), Antunsuhono (1953), S. Sastrasoepadma (1957), Hadiwidjana (1967), Poedjosoedarmo (1979), dan Purwadi (2005) pada umumnya membagi sistem unggahungguh bahasa Jawa yang pokok atas 3 kelompok ragam tingkat tutur (unggah-ungguh basa), yaitu (1) ragam ngoko, (2) ragam madya, dan (3) ragam krama. Masing-masing tingkat tutur tersebut dirinci lagi menjadi sub-sub bagian yang lebih spesifik. Selain itu ada pula yang menambahkan Basa Bagongan atau Basa Kedhaton sebagai kelengkapannya. Basa Bagongan adalah sejenis ragam bahasa Jawa yang digunakan sebagai alat komunikasi khusus antarraja dengan abdi dalem di kraton Yogyakarta saat acara formal (paseban); sedang Basa Kedhaton merupakan bahasa Jawa sejenis yang digunakan di kraton Surakarta (Poerwadarminta, 1953:9-12; Antunsuhono, 1953:8-9).

Ragam ngoko umum digunakan penutur (O1) dalam berkomunikasi dengan teman akrab atau untuk tujuan menciptakan suasana akrab. Misalnya saat seseorang berbicara dengan teman, adik, orang yang lebih muda, dan ditandai dengan pemakaian kosa kata dengan ngoko yang biasa dan tidak bernilai hormat. Namun dalam konteks tertentu pemakaian ragam ngoko diselipkan unsur leksikon krama (inggil) karena pertimbangan umur dan hormat disebut ngoko andhap (antyabasa/basa antya).

Ragam krama biasanya digunakan dalam proses komunikasi resmi. Dalam kaitan ini penutur (O1) menempatkan dirinya lebih rendah dan dengan menggunakan pola dan pilihan kata tertentu (krama) dimaksudkan untuk menghormat mitra bicara (O2). Ragam madya biasanya digunakan untuk berkomunikasi dengan mereka yang disegani, namun telah akrab. Hal demikian dimaksudkan agar proses komunikasi dapat lebih akrab namun penutur tetap tidak meninggalkan 
subasita 'sopan santun'. Demikian pula penggunaan ragam madya dalam kondisi tertentu dapat pula sebagai indikasi bahwa penuturnya belum menguasai penggunaan ragam krama secara baik.

Dalam pemakaian, antarragam tersebut sering terjadi interferensi antarkosa kata, sehingga sering sulit membedakannya. Namun demikian, selain petunjuk hadirnya kata-kata khas kowe (ngoko), sampeyan (madya), panjenengan (krama), untuk identifikasi tingkat tutur dalam bahasa Jawa dapat dikenali pula melalui petunjuk pemakaian kata tugas atau kata keterangan, misalnya: niki 'ini', niku 'itu', nika 'itu' menjadi menika, empun-sampun 'sudah', ajeng-badhe 'akan', saniki-samenika 'sekarang', teng-dhateng 'ke', mengkehmangkeh 'nanti' (Poedjosoedarmo, 1979).

\section{BAHASA PEDALANGAN}

Bahasa pedalangan, khususnya pedalangan wayang kulit purwa secara umum menggunakan bahasa Jawa. Karakteristik bahasa Jawa yang digunakan variannya relatif lengkap. Tidak saja pemakaian ragam bahasa sehari-hari yang umum dijumpai di masyarakat, namun pengguanaan ragam indah (renggabasa) yang merupakan ciri bahasa sastra sebagai refleksi rasa seni muncul sepanjang pagelaran wayang kulit itu berlangsung. Secara fungsional, ragam bahasa Jawa yang umumnya turut mendukung seni pedalangan wayang kulit, antara lain (1) ragam ngoko, (2) ragam madya, (3) ragam krama, (4) ragam sulukan, (5) ragam janturan, (6) ragam antawecana, (7) ragam sasmita, dan (8) ragam panyandra. Berdasarkan aspek pembentukannya yang memerlukan sentuhan aspek seni, estetika, dan aturan khusus, maka ragam (4) s/d (8) sebagaimana dijelaskan diatas tergolong kelompok ragam renggabasa 'ragam indah'.

Ragam ngoko yaitu jenis ragam bahasa Jawa yang menjadi dasar pembentukan varian ragam bahasa Jawa lainnnya (basa ngoko iku bebaku lajering basa Jawa). Bagi suku Jawa, pemerolehan dan penguasaan ragam bahasa ini menduduki peringkat pertama (awal) sebelum anak mengenal dan menguasai ragam-ragam lainnya (madya dan krama). Dalam tataran aplikasi, ragam ngoko digunakan sebagai alat komunikasi paling luas dan menempatkan $\mathrm{O} 1$ dan $\mathrm{O} 2$ dalam konteks akrab (teman). Pemakaian ragam ngoko juga dapat dilakukan oleh orang tua kepada orang yang lebih muda, antarteman sebaya, atasan kepada bawahan, orang yang baru belajar bahasa Jawa, ngunandika (berbicara pada diri sendiri), atau berbicara untuk tujuan tertentu (Dikbud, 1946:64; Poerwadarminta, 1953: 9-11; Purwadi, 2005:14-15).

Ragam madya adalah jenis ragam bahasa Jawa yang di dalamnya terdapat unsur kosa kata madya (sampeyan, dika, pripun, nika, niki, niku, dll.), dan penggunaan afik ngoko pada kata krama (didhahar, dibetakake) saat seseorang berbicara pada pihak lain. Bentuk ragam ini (madya) secara makna berkonotasi hormat, tetapi karena alasan tertentu (umur, kedudukan, hubungan sosial), derajat kualifikasi hormat ragam tersebut lebih rendah dibandingkan ragam krama. Ragam madya umum dijumpai pada kelompok anakanak/orang yang belajar ragam krama, pejabat muda pada pembantunya yang lebih tua, atau mertua pada menantunya (Dikbud, 1946:68; Poerwadarminta, 1953: 12; Purwadi, 2005:1415).

Ragam krama yaitu jenis ragam bahasa Jawa tingkat hormat. Dalam pemakaiannya, ragam ini ditujukan untuk menghormati orang yang diajak berbicara (O2). Mereka yang termasuk dalam kategorial pihak yang layak dihormati sehingga penggunaan ragam krama menjadi keharusan substansial, yaitu: (1) orang yang lebih tua, (2) sesepuh, (3) atasan/ pimpinan, (4) guru, (5) teman baru, dsb. Orang yang lebih tua (ayah/ibu dan saudaranya, kakek/nenek, kakak), layak dihormati karena perannya dalam keluarga. Sesepuh (tokoh masyarakat) dan atasan/pimpinan dalam budaya Jawa juga termasuk kelompok yang harus dihormati. Guru dalam segala kedudukannya (guru sekolah, guru ngaji, guru silat, dll) juga wajib dihormati karena perannya dalam pencerahan hidup. Demikian pula kepada teman baru, sebagai ungkapan rasa 
hormat dan bersahabat maka pada tahapan awal, pemakaian ragam krama selain untuk tujuan hormat, juga sebagai petunjuk kadar etika seseorang (Dikbud, 1946:72; Poerwadarminta, 1953: 10; Purwadi, 2005:1415).

Ragam sulukan yaitu jenis ragam bahasa pedalangan berbentuk syair yang dinyanyikan (tembang) dalang. Isinya merupakan petunjuk, isyarat, sindiran, mengenai keadaan tokoh tertentu dan sebagai antara dalam suatu adegan yang akan dipertunjukan atau tentang perubahan perangai tokoh yang beraksi. Manfaat sulukan dalam dunia pewayangan ditujukan untuk membangun suasana yang sedang diceritakan. "Gunane suluk pedalangan iku kanggo ambangun swasana, swasananing kahanan kang lagi dicaritakake. Swasana kang dibangun warna-warna, mulane suluke iyo gonta-ganti: swasana susah, gembira, lega, kacuwan, sereng, lan kendho" (Padmosoekotjo, 1958:112-114). Bahasa sulukan umumnya merupakan bahasa yang sifatnya standar (baku dan beku), sehingga dalam proses penguasaannya lebih menekankan pada aspek hapalan daripada aspek kreasi.

Ragam janturan merupakan varian dari penggambaran suasana tertentu, baik menyangkut tokoh maupun kebesaran, keelokan, atau kebobrokan situasi tertentu (kerajaan). Jika sulukan itu penyampaiannya dilagukan (ditembangkan), maka janturan disampaikan dengan gaya narasi biasa tetapi reflektif. Pendapat lain mengatakan bahwa janturan sebagai pengungkapan bahasa dengan cara dideklamasikan (Yuwana, 2000:219).

Ragam antawacana, merupakan eksplorasi gaya kemampuan dalang dalam membedakan gaya suara (vokal) dan karakter tiap tokoh wayang secara spesifik (Sastroamidjojo, 1964:93). Sebagaimana para pecinta budaya Jawa dan dunia pewayangan, bahwa tokoh sentral yang umum diketahui dalam seri Ramayana dan Mahabarata, tentulah sangat kenal dengan logat bahasa dan karakter tokoh Ramawijaya (lembut), Rahwana (sombong), dan Kumbakarno (berwibawa). Demikian pula dengan tokoh Kresna (branyak 'ringan dalam berbicara'), Bima (lambat berwibawa), Dursasana (keras dan sombong), dan lain sebagainya.

Ragam panyandra, yaitu sebagai bentuk ungkapan bahasa yang bernilai perumpamaan. Nyandra ateges nggambarake kaendahan utawa kahanan sarana pepindhan (Padmosoekotjo, 1958:101). Artinya bahwa nyandra mengandung makna menggambarkan atau melukiskan suatu keindahan atau keadaan tertentu menggunakan bentuk perumpamaan. Misalnya, saat dalang "nyandra" kecantikan istri setia Arjuna: Yen cinandra sulistiyane sang Dewi Warasumbadra, pranyata kurang candra luwih ing warna (Jika diuraikan kecantikan Sang Dewi Warasumbadra, kata-kata pun tidak cukup untuk menguraikan kecantikannya), dsb.

Ragam sasmita yaitu bentuk ungkapan yang digunakan dalang untuk meminta gendhing atau jenis tembang tertentu. Kata yang digunakan untuk mengisyaratkan jenis tembang tertentu biasanya tidak langsung dan umumnya dipadukan secara tersamar dalam struktur kalimat tembang. Oleh karena itu bagi mereka yang memahami budaya Jawa, khususnya seni sastra, hal semacam itu disebutnya dengan sasmitaning tembang (Soetrisno, 2004:6-8). Hal semacam itu berlaku pada jenis sastra lama dan juga seni drama tradidisional, termasuk pedalangan. Manawa dalang (sajrone mayang) mbutuhake gendhing apa bae mung kari ngabani marang para niyaga. Prentahe dalang marang niyaga iku ora mung dilairake nganggo ukara sawetara bae, nanging sinamun ing pralambang utawa sasmita 'Jika dalang meminta gending kepada niyaga (tukang menambuh gamelan) tidak disampaikan secara langsung, tetapi menggunakan perlambang' (Padmosoekotjo, 1958:83-84). Misalnya, wacana ungkapan: Kang pinucung, sakawit met dongengipun... (perminataan tembang pocung), Kasmaran ingkang pinuji,...(permintaann tembang asmaradana), Wancine wis paripurna, ...(pertanda gendhing pathet manyura). 


\section{ANALISIS BAHASA PEDALANGAN}

Sebagaimana dijelaskan di atas, secara teoritik ragam bahasa Jawa berdasarkan aspek tingkat tutur yang fungsional di masyarakat, terbagai atas tiga kelompok, yaitu ragam ngoko, ragam madya, dan ragam krama. Karakteristik masing-masing ragam tersebut berkaitan dengan sikap O1 dalam memperlakukan $\mathrm{O} 2$ sesuai dengan etika budaya yang berlaku dalam masyarakat Jawa.

Identifikasi suatu ragam terletak pada hadirnya jenis leksikon (kosa kata) tertentu yang secara spesifik berbeda baik secara morfologis maupun fonologisnya, seperti kata: kowe, omong, arep, mangan, segara (ngoko); sampeyan, wicanten, ajeng, nedhi, seganten (madya); dan panjenengan, ngendika, badhe, dhahar, samodra (krama). Berdasarkan hasil identifikasi data bahasa pedalangan Ki Enthus Susmono dalam pentas seni pakelirannya, secara umum cukup tergambarkan dengan jelas bahkan terdapat pengembangan yang signifikan dari sisi variasi pemakaian ragamnya. Ilustrasi fragmen berikut yang merupakan fakta rekaman dialog antara Raja Puntadewa (PW), Semar Badranaya (SM), Raden Arjuna (AJ), Raden Nakula (NK), dan Raden Sadewa (SD) akan dapat menjelaskannya secara lebih konkrit.

(1) PW: Kakang Semar Badranaya! (DLI, H14)

'Kakak Semar Badranaya!'

(2) SM: Eh, kula Ndara? (DLI, H14)

'Iya, ada apa Tuan!'

(3) PW: Tekane Petruk lawan Bagong sajak nyalawadi. (DLI, H14)

'Kedatangan Petruk dan Bagong agaknya kok mencurigakan.'

(4) SM: Boten namung nika Ndara, kula mireng "Tembang rawat-rawat mbok bakul sinambi wara”, Ndara Werkudara saniki pun damel kekiyatan, nglempakaken Raden Gathotkaca, Anoman lan sapiturutipun. Mbenjang-enjang badhe nantang perang kaliyan sampeyan, Den! (DLI, H14)

'Bukan hanya itu Tuan! Saya mendengar kabar yang meyakinkan bahwa Tuan Werkudara sekarang telah menyusun kekuatan dengan cara mengumpulkan raden Gatutkaca, Anoman, dan lain sebagainya. Besok pagi dia akan datang untuk menyerang, Tuan!'

(5) NK/SD: Kakang Mas, Kakang Mas kula nyuwun pangayoman kakang Mas! (DLI, H14).

'Kakak, saya mohon perlindungan.'

(6) AJ: Kanjeng Kaka Prabu, panjenengan kula aturi ngancik dhateng kawicaksanan. Menawi sampun ngaten ingkang dados pratingkahing kakang Bratasena, mangsa borong dhumateng paduka. (DLI, H15).

'Kakak Prabu! Jika perilaku Kakak Bratasena sudah di luar batas kewajaran, maka semuanya saya serahkan pada kebijaksanaanmu!'.

Wacana tutur (1) sampai dengan (6) merupakan petikan dialog dalam suatu pertemuan resmi kenegaraan (pasamuan agung) di negeri Amarta. Secara linguistis, interaksi bahasa Jawa yang digunakan tersebut terdapat 3 jenis ragam, yaitu ragam ngoko, madya, dan ragam krama yang secara stratifikasi sosial memperlihatkan posisi dan kedudukan masing-masing dalam struktur sosial masyarakatnya (Jawa). Misalnya, saat Prabu Puntadewa memanggil Semar abdinya: “Kakang Semar Badranaya!”(1), dan "Tekane Petruk lawan Bagong sajaknyalawadi" (3).

Kedua data wacana tutur tersebut secara tipologis termasuk ke dalam tipe ragam ngoko. Secara budaya, penerapan ragam itu benar, sebab dari aspek kedudukan dan status sosial ia adalah seorang raja. Dalam tradisi Jawa, seorang atasan/raja (karena kedudukan dan power) boleh berkomunikasi menggunakan ragam ngoko kepada bawahannya. Sebaliknya, Semar dan Arjuna serta adiknya (Nakula/ Sadewa) menjawabnya dengan menggunakan 
ragam krama. Seperti contoh (2) "Eh, kula Ndara?", (5) "Kakang Mas, Kakang Mas kula nyuwun pangayoman kakang Mas!", dan (6) "Kanjeng Kaka Prabu, panjenengan kula aturi ngancik dhateng kawicaksanan. Menawi sampun ngaten ingkang dados pratingkahing kakang Bratasena, mangsa borong dhumateng paduka", sebab Semar berbicara kepada rajanya, dan Nakula, Sadewa. Arjuna yang secara usia ia lebih muda dan berbicara kepada kakak tertua dan sekaligus seorang raja menggunakan bahasa krama.

Namun hal yang agak berbeda dilakukan Semar saat berbicara kepada Raja Puntadewa. Ia bertutur menggunakan ragam madya (4), sebab yang berbicara selain Semar sebagai abdi, juga dalam posisinya sebagai dewa ngejawantah (penjelmaan Sang Hyang Ismaya) yang sangat disegani di Kadewatan (tempat para dewa), sehingga pemakaian ragam madya yang nampak pada pemakaian leksikon: nika (punika) 'itu', saniki (sapunika) 'sekarang', pun (sampun) 'sudah', dan sampeyan (panjenengan) 'anda', juga dibenarkan karena alasan tertentu.

Selain 3 (tiga) ragam di atas, dari fakta bahasa pedalangan Ki Enthus terdapat pula ragam lain yang secara karakteristik memperlihatkan kekhasannya sebagai bentuk interaksi sosial. Contoh-contoh kutipan wacana tutur berikut menggambarkan suatu perilaku bahasa yang secara semantis memiliki dampak berbeda (kasar) bagi pihak pendengarnya, apalagi yang menjadi obyek tujuan. Secara semantis psikologis model cakapan yang kasar dan berdampak menyakitkan ini tergolong ragam kasar sebagaimana tercermin pada kutipan fragmen wacana tutur (7) s/d (10), yang merupakan bagian dialog antara Semar (SM) dengan Prabu Duryudana, suami Limbuk (BJ) dengan istrinya.

(7) SM: “... Niku mung gegeden abab, kakeyan cangkem, niku nyatane gak enek. Napa malih nek janji-janji karo rakyat, wah gedebus muruh-muruh cangkeme lagi kampanye muruh nganti ababe ambune buacin, ketemune ketlepak ya paling- paling gedebus. ..." (DLI, H3).

'Pejabat semacam itu hanya hanya pandai membual tapi jauh dari kenyataan. Apalagi jika sedang kampanye di depan rakyat, ia berjanji dan berbicara sampai mulutnya berbusa-busa, namun jika sudah menjadi pemimpin segera melupakan janjinya.'

(8) SM: “... Nek ora gelem meneng takdhupak dagangane monyor engko. Aja diserokseroke! Ayo kandhani, nek ora gelem ongko taklaraksaewonge pisan. ...!" (DLI, H9).

'Jika tidak mau diam, saya tendang dagangannya hingga rusak. Jangan terlalu keras suaranya, jika masih membandel saya seret sekalian dengan penjualnya.'

(9) SM: “... Heeh, tukang jamu! Speaker sampeyan mang cilikne, ngganggu penonton! Pilih mandheg apa pilih ditendhangi. Diancuk sampeyan. ... Dilirihne! Dhapuranmu iku melu aku, melu merma, melu nggolek rejeki. Ngganggu karo sumbere sing nggolekne rejeki! ..." (DLI, H19).

'Heeh, tukang jamu, speaker-mu tolong dikecilkan mengganggu penonton! Pilih berhenti atau ditendangi? Diancuk kamu ya! Dikecilkan! Kamu itu saya, ikut berjualan mencari rejeki. Mengganggu saya!'

(10) BJ: “... Jan-jane pejabat sing ora nanggap Enthus merga wedi dikritik iku gobloggobloke pejabat...." (DLI, H2O).

'Sebenarnya, pejabat yang tidak mau mengundang Enthus karena takut dikritik adalah sangat bodoh....'

Secara semantis linguistis (makna denotatif), keempat kutipan wacana bahasa di atas tergolong ragam kasar. Hal itu didasarkan atas nilai rasa yang terbangun karena hadirnya kata: gegeden abab 'besar mulut', kakeyan cangkem 'banyak bicara', nggedebus muruhmuruh cangkeme 'berbicara sampai mulutnya berbusa-busa', ababe ambune buacin 
'napasnya bau busuk' pada data (7) yang digunakan untuk memberikan predikat buruk pada para pejabat pada umumnya. Penggunaan unsur kata seperti: takdhupak 'saya tendang', monyor 'muka bengkak', taklarak 'saya seret', ditendhangi 'saya tendangi', Diancuk sampeyan 'sialan kamu', dan dhapuranmu 'bentukmu, mukamu' pada data bahasa (8) dan (9) yang ditujukan pada tukang jamu. Demikian pula penggunaan unsur kata seperti: gobloggobloke pejabat 'pejabat bodoh' pada kutipan (10).

Istilah-istilah itu pada tataran budaya Jawa merupakan pernyataan keras dan mengandung konotasi makna yang sangat kasar, menyakitkan, menyudutkan, sehingga umumnya orang yang menjadi alamat (dituju) akan sangat tersinggung serta marah. Namun pernyataan kasar semacam itu justru banyak mendapatkan respon positif dari penonton karena dipandang mewakili perasaan masyarakat secara umum. Apalagi berkaitan dengan kritikan tajam pada para pejabat yang tidak amanah (bandel, tidak tahu diri, korup) dan menimbulkan kesengsaraan pada masyarakat banyak, maka apa yang dilakukan $\mathrm{Ki}$ Enthus dianggapnya tepat sebab obyek sasaran $(\mathrm{O} 2)$ dianggapnya sudah di luar batas toleransi.

Namun, adakalanya kehadiran unsur kata-kata kasar tersebut tidak menimbulkan ketersinggungan karena konteks yang secara sengaja dibangun untuk kepentingan intermezo (melawak) atau merupakan bagian dari "sapaan akrab" (teman) kelompok masyarakat tertentu. Hal itu tergambar saat bintang tamu Priya Aljabar (PA) menimpali penggunaan istilah "kasar" Ki Enthus (BJ) dalam suatu dialog dengannya atau dengan sindhen pada selingan pertunjukan seni pakelirannya. Penggalan fragmen dialog berikut memberikan kejelasan tentang hal tersebut.

\section{PA: Aku wit mau tak ati-ati. Nang Surabaya dikenal misuhan, la nok kene malah nerus, diancuk kieh! Ya Allah! (DLI, H30).}

'Saya berusaha untuk hati-hati karena di Surabaya di kenal bahasanya kasar, namun di sini dipancing terus kurang ajar 'diancuk'. YaAllah!'

12. BJ: Cangkemu ora usah nggambleh, iyeeeh! (DLI, H36).

'Mulutmu tidak usah banyak bicara, yah?'

13. BJ: Wis gatel yo saiki? (DLI, H36).

'Kamu sudah "gatal” ya sekarang?'

Pernyataan kata diancuk kieh 'sialan' pada kutipan dialog (11) antara Ki Enthus dengan Cak Priyo sekalipun menggunakan ungkapan kasar (pisuhan ala Surabaya) yang ditangkap pendengarnya adalah kesan "lucunya" karena dikemas dengan konteks guyonan 'melucu'. Demikian pula ungkapan kata cangkemu 'mulutmu' (12), dan gatel 'ingin dikawini' (13), sekalipun kata-kata tersebut sangat kasar untuk konteks "ke-Jawaan" (cangkem 'mulut', gatel 'birahi'), namun karena diciptakan sengaja untuk memancing situasi lucu, maka menjadikan kata yang berkonotasi kasar menjadi tidak terasakan bagi pihak yang dituju. Apalagi sindhen sebagai bawahan dalang, maka apa yang ditujukan kepadanya (pujian, olok-olok) menjadi bagian konsekuensi profesi.

Selain ragam kasar, dalam dunia pedalangan terdapat pula ragam lain yang umumnya hidup di lingkungan keraton Jawa (Yogyakarta dan Surakarta). Dalam dunia pedalangan karakter bahasa tersebut direfleksikan dalam fragmen paseban jejer kedhatonan 'rapat kerajaan' oleh Raja Puntadewa (PW) dan Arjuna (AJ), Jejer Kadewatan 'perbincangan di Suralaya' yang diwakili oleh Bethara Darmo (BD).

14. PW: Hyang sukma adilinuwih payungana panjenenganingsun apepura pujabrata. Ingsun salah nyuwun pangapura. Yayi Arjuna! (DL1, H7).

'Ya Tuhan Yang Maha kuasa lindungilah aku dan maafkanlah semua kesalahanku.'

15. AJ: Wonten dhawuh timbalan, Kanjeng Kaka Prabu! (DLI, H7). 
'Iya, saya kakak Raja.'

16. BD: Kakang Semar, wiwit nalikane Puntadewa isih sinau aneng pengguron, pesantren Sokalima, Panjenengan Ulun wis dinuta dening Sang Hyang Pada Winenang kinen ngendhangi utawa momong. (DLI, H52).

'Kakak Semar, sejak Puntadewa masih belajar di perguruan Sokalima saya sudah diperintahkan untuk menjenguk, mengawasi, dan melindungi.'

Data kutipan (14) sebenarnya merupakan ungkapan doa yang biasa diucapkan seorang raja atau resi saat mengawali suatu pembicaraan. Hal itu merupakan gambaran bentuk keterikatan dan penyerahan diri seorang mahluk kepada Tuhannya (manunggaling kawula gusti) yang terdapat dalam keyakinan kejawen pada budaya Jawa. Isinya tentang permohonan perlindungan kepada Tuhan (Hyang Suksma) agar selalu dilindungi dan diberkati segala tindakan serta dimaafkan segala kesalahannya. Dalam ungkapan data (14) dan (15) terdapat penggunaan leksikon (kata) seperti: Hyang Suksma 'Tuhan', adilinuwih 'yang maha segalanya', panjenenganingsun 'saya', pujabrata 'ibadah, samadi', wonten dhawuh timbalan 'apa tuan', dan Kanjeng Kaka Prabu 'kakak Raja'. Demikian pula pada data wacana (16) terdapat pemakaian ungkapan kata panjenengan ulun 'saya untuk dewa', dinuta 'diperintah, diutus', dan Sang Hyang Pada Winenang 'rajanya para dewa'. Istilah-istilah semacam itu merupakan sistem linguistik yang khas dan hanya dijumpai sebagai media interaksi terbatas di lingkungan kerajaan, pertapaan, dan kadewatan. Karakteristik bahasa Jawa semacam itu dinamakan ragam Basa Kedhaton atau Basa Bagongan.

Hal yang berbeda dijumpai melalui data bahasa pedalangan, yaitu ragam sulukan dan janturan. Keduanya memiliki kesamaan fungsi, yaitu untuk menggambarkan sesuatu keadaan (senang, damai, indah, agung, marah, sedih, cinta kasih), tetapi berbeda dalam hal bentuk. Sulukan ungkapan syairnya disampaikan dengan cara dinyanyikan, dilagukan (ditembangkan), sedangkan janturan diungkapkan dengan gaya prosa (diceriterakan). Contoh fragmen interaksi bahasa model sulukan oleh Dalang (DL) dan Panjak (PJ).

17. DL: Pindha bumi gonjang-ganjing. Ong ...ong! Malebu guntur, tumembak ing jalanidhi. Penyunira kumambangkambang ...eh...eh. (DLI, H2).

'Bumi terasa bergoncang-goncang dan dentuman halilintar menyambar samudra sehingga banyak penyu yang mati mengambang karenanya.'

18. DL: Maridho sing prayitno, sumurup titiyoni-gondoyoni ... ooong, ooong...! Lulang kang ginambar jalmo ..., Jalma ratu, pujangga kang darbeni. Mesjid agung, Demak kang minangka kawitane. Sunan Kalijaga kang anganthi wayang, kalawan Sunan Giri, kalawan Kanjeng Sunan Bonang, kang minangka tepapalupi... ! (DLI, H9)

'Berhati-hatilah/ingatlah terhadap berbagai isyarat dan tuntunan yang disampaikan dari mimpi yang ada dalam tontonan wayang sebagai karya besar para raja dan pujangga. Pengembangannya diawali oleh Sunan Kalijaga sejak berdirinya Masjid Agung Demak, dan dilanjutkan oleh Sunan Giri dan Sunan Bonang yang ajarannya dapat dipercaya.'

19. DL: Bumi gonjang-ganjing langit kelapkelap katon, lir gincang sang maweh gandrung. Eh...eh! (DLI, H46).

'Dunia terasa berputar dan pandangan terasa kabur bagaikan kegundahan hati orang yang sedang jatuh cinta.'

20. PJ: Wulan Mulud lahiripun Kanjeng Nabi sang Guru sejati, ramane Raden Abduloh, ibune Dewi Aminah, aneng Mekah lahiripun, ing Madinah sedanipun ...! (DLI, H39). 
'Bulan Maulud saat kelahiran Kanjeng Nabi seorang guru sejati. Ia adalah putra Raden Abdulah dari seorang istri bernama Dewi Aminah. Nabi sendiri lahirnya di Mekah dan meninggalnya di Madinah.'

Data wacana sulukan (17) digunakan dalang untuk menggambarkan suasana hati raja Duryudana yang terkejut karena kedatangan Semar Badranaya yang tidak biasa dan tidak pernah terjadi sebelumnya. Keterkejutan itu diwakili oleh ungkapan puitis Pindha bumi gonjang-ganjing (hatinya seperti berguncangguncang) untuk menggambarkan batinnya yang ragu dan tidak percaya. Ketidakpercayaannya itu menimbulkan perang batin yang hebat dengan ilustrasi gaya hiperbola Malebu guntur, tumembak ing jalaniti. Penyunira kumambangkambang (Seperti ledakan guntur di samudra yang mengakibatkan banyak kematian).

Data wacana sulukan (18) digunakan dalang untuk menggambarkan cara mencari solusi jika menghadapi masalah dengan mengingat petuah leluhur yang direfleksikan dalam seni pewayangan dalam ungkapan syair Maridho sing prayitna, sumurup titiyonigondoyoni. Lulang kang ginambar jalma, Jalma ratu, pujangga kang darbeni 'Wayang sebagai karya besar para raja dan pujangga banyak mengandung tuntunan yang digunakan sebagai cermin dan pedoman hidup'. Hal itu juga dicontohkan para wali yang tergambar pada ungkapan syair Sunan Kalijaga kang anganthi wayang, kalawan Sunan Giri, kalawan Kanjeng Sunan Bonang, kang minangka tepapalupi 'Sunan Kalijaga, Sunan Giri, dan Sunan Bonang yang memanfaatkan nilai-nilai dalam wayang sebagai ajaran hidup'.

Data wacana sulukan (19) merupakan bentuk penggambaran amarah Prabu Puntadewa yang telah berubah menjadi raksasa kepada Bima yang dianggapnya sebagai penghianat negara, dan Bima sendiri kebingungan karena harus berhadapan (berperang) dengan kakak yang dihormatinya. Hal itu tergambar dari ungkapan syair puitis Bumi gonjang-ganjing langit kelap-kelap katon, lir gincang sang maweh gandrung
'Bumi terasa bergoncang dan pandangan nampak kabur, sebagaimana kebimbangan hati orang yang sedang dilanda cinta'. Puntadewa terguncang hatinya karena mendengar adik yang disayangi mau memberontak padanya, dan sebaliknya Bima bingung karena tuduhan itu tidak benar, apalagi harus berperang dengan kakak yang sangat dihormatinya.

Berbeda halnya dengan 3 model sulukan sebelumnya, wacana sulukan (20) merupakan kreasi Ki Enthus untuk memperlihatkan eksistensinya sebagai dalang yang bergaya "pesisisiran" sehingga kental dengan nuansa ke-Islamannya. Ia menciptakan gaya "suluk puji-pujian" kepada Nabi Muhammad dan sejarah hidupnya sebagai utusan Allah, melalui suara panjak 'sinden lakilaki' yang dibawanya, sebagaimana tergambar pada syair berikut: Wulan Mulud lahiripun Kanjeng Nabi sang Guru sejati, ramane Raden Abduloh, ibune Dewi Aminah, aneng Mekah lahiripun, ing Madinah sedanipun 'Nabi Muhammad dilahirkan pada bulan Maulud di Mekah dari seorang ayah bernama Abdullah dan ibunya Siti Aminah. Beliau meninggal dan dikuburkan di Madinah'.

Ragam indah selain digunakan seorang dalang (Ki Enthus) dalam bentuk wacana sulukan sebagaimana contoh-contoh di atas, juga diperlihatkan pengguna-annya dalam bentuk bahasa janturan (ragam janturan). Sebagaimana dijelaskan di depan bahwa janturan adalah termasuk model suluk dalam bentuk prosa. Contoh pragmen wacana janturan oleh dalang (DL) berikut dapat menjelaskannya.

21. DL: Cep klakep parekang padha nyabawa. Ature Ki Lurah Semar Badranaya mawa racun, mawa wisa tumandhuk jajanipun prabu Puntadewa denampet. Dereng ngantos ngunandika, praptane Petruk karo Bagong ...(DLI, H11).

'Prabu Puntadewa dan adik-adiknya terdiam dan terkesima mendengar pernyataan Semar yang sangat tajam dan menyudutkan. Namun belum sempat menjawab tersela datangnya Petruk dan Bagong.' 
22. DL: Kabranang Prabu Puntadewa. Apa ta sababe tan teguh Prabu Puntadewa? Karana rongeh penggalihe, durung bisa menep, durung bisa manunggalake pancadriyane, isih worsuh sajeroning penggalih karana estuning manah. Sang Prabu Puntadewa koncatan Sang Hyang Bethara Darmo, kang sarta Prabu Puntadewa wus koncatan pusaka sekti kang aran jimat kalimasada. Horeg palangkangane Sang Prabu Puntadewa, ical jatining wujud, jleg dadi brahala, buta gedhe ngebaki jagad raya. Geger Ngamarta. (DLI, H.15).

'Prabu Puntadewa terbakar emosinya karena tidak dapat berpikir jernih dan gagal mengendalikan hawa napsu. Akhirnya ia kehilangan pamor Bethara Darmo dan jimat kalimasada yang membimbingnya dan berubahlah menjadi raksasa besar yang menakutkan.'

23. DL: Mangsuli cariyos ing ngajeng, macan Matenggo Kyai Jenar kaliyan bantheng Kyai Langking, pancabakah sami pating galungsar, kentekan tenaga sami lempelempe. Sakala kalebon Bethara Wisnu kaliyan Bethara Darmo, ngalempreh Narendra Dwarawati kaliyan Narendra Puntadewa gapyuk sami rerangkulan sakala nglenggana dhateng sadaya kalepatan. (DLI, H54-55).

'Mengulangi ceritra di depan, harimau Kyai Jenar dan banteng Kyai Langking bertempur habis-habisan sampai lemas. Setelah keduanya sadar karena kemasukan Dewa Wisnu (Kresna) dan Dewa Darmo (Puntadewa) maka ia segera berangkulan dan saling meminta maaf.'

Janturan (22) merupakan akumulasi dari kegalauan hati dan terbakarnya emosi Prabu Puntadewa setelah kedatangan Petruk dan Bagong serta desakan (hasutan) Semar yang meyakinkan. Hal yang membuat dirinya marah besar (emosi memuncak) adalah informasi bahwa Bima, adiknya telah menyusun kekuatan dan hendak segera menyerang Amarta dan adik-adiknya yang lain (Arjuna, Nakula dan Sadewa) ketakutan meminta perlindungan. Prabu Puntadewa seketika murka dan berubah menjadi raksasa besar yang sangat perkasa serta menakutkan untuk menghadapi Bima dan sekutunya.

Berbeda halnya yang terjadi pada janturan (23), ki dalang mengungkapkannya sebagai gambaran sebelum peristiwa terjadi. Janturan itu mengilustrasikan peristiwa yang akan terjadi, yaitu masuknya Bethara Darmo dan Bethara Wisnu masuk ke dalam tubuh Puntadewa Kresna. Keduanya segera tersadar dan akhirnya saling minta maaf.

Berdasarkan keseluruhan data yang berkaitan dengan aspek tingkat tutur, maka pola hubungan yang secara fungsional melekat pada bentuk interaksi antar tokohnya cukup variatif. Hal itu menggambarkan visi dalang yang ingin merefleksikan drama pertunjukan wayang sebagai gambaran nyata kehidupan masyarakat penonton dan budaya Jawa pada umumnya. Dalam faktanya kehidupan masyarakat (Jawa) menggunakan bahasa sebagai media interaksi sosialnya cukup lengkap mulai dari yang secara semantis berkonotasi paling halus hingga yang paling kasar dengan latar belakang yang menyertainya.

Dengan demikian pagelaran wayang Kulit yang ditampilkannya (termasuk aspek bahasanya) bukan sekedar hasil pengolahan pikir yang imajinatif sifatnya, tetapi lebih merupakan "potret" budaya yang berkembang secara alamiah di lingkungan masyarakat penonton. Hal yang berkaitan dengan pemakaian bahasa yang alamiah dalam seni pakeliran, diharapkan dapat lebih mempermudah penonton dalam pemahaman isi ceritra dan apresiasi nilai kesastraannya secara baik.

Hal yang lebih penting adalah bahwa seni pakeliran Ki Enthus berusaha mendekatkan jarak antara pertunjukan wayang kulit sebagai seni (budaya) tradisional dengan karakter penonton yang berpola pikir modern (global). Cara yang dilakukan Ki Enthus yaitu, dengan mengembangkan struktur lakon secara lebih rasional dan bahasa sebagai instrumennya 
dimodifikasi secara natural tetapi bervisi univesal (global). Keuniversalan visi bahasa pedalangannya tidak hanya meliputi bahasa Jawa sebagai basis budaya wayang kulit, tetapi ia melihat bahwa potret masyarakat Jawa sekarang tidak seperti saat kelahiran wayang pada awalnya, yang cenderung ekabahasawan. Masyarakat Jawa saat ini sudah demikian maju dan sama seperti suku dan bangsa lain di dunia, masuk dalam abad modern dan menguasai banyak bahasa (dwibahasawan). Dengan visi modernitas inilah Ki Enthus memasukan unsur bahasa Indonesia, Inggris, Arab, Sunda, dan lain sebagainya. Hal itu selain untuk mengubah paradigma lama tentang seni pakeliran (full Javanism) yang abstrak menjadi wayang sebagai potret budaya Jawa yang selaras di masa lalu, masa sekarang, dan masa datang, juga itu agar wayang kulit yang adiluhung itu dikenal lebih luas. Pola hubungan pemakaian ragam bahasa pedalangan Ki Enthus Susmono berdasarkan tingkat tuturnya tergambar dalam bagan berikut.

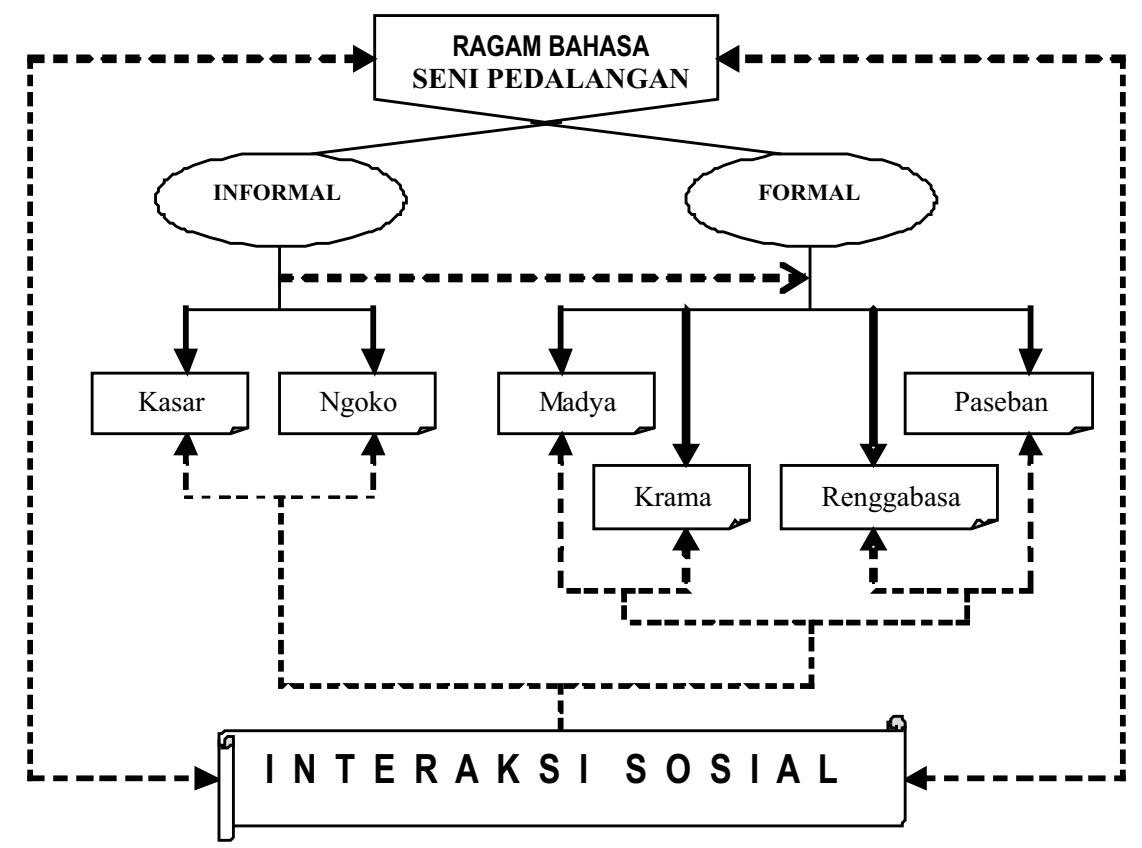

Berdasarkan fakta analisis (penelitian) bahasa pedalangan (Ki Enthus Susmono) yang berhasil diidentifikasi terbuktilah bahwa ragam bahasa Jawa tidak sesederhana itu, tetapi berkembang secara lebih luas sebab tuntutan konteks kebutuhan. Hal itu penting dikemukakan agar potret pemakaian bahasa
Jawa diketahui secara utuh sehingga ekspektasi teoritiknya memiliki nilai keuniversalan. Dari data analisis di atas, tingkat tutur bahasa Jawa terdapat pengembangan ragam yang selama ini tidak diperhitungkan. Tabel berikut menggambaran secara komparatif antar teori konvensional dan fakta penelitian. 


\begin{tabular}{|c|c|}
\hline \multicolumn{2}{|c|}{ TINGKAT TUTUR (UNGGAH-UNGGUH BASA) } \\
\hline Data Konvensional & Data Penelitian \\
\hline $\begin{array}{l}\text { (1) Ragam Ngoko } \\
\text { (2) Ragam Madya } \\
\text { (3) Ragam Krama } \\
\text { (4) Ragam Bagongan }\end{array}$ & $\begin{array}{l}\text { (1) Ragam Kasar } \\
\text { (2) Ragam Ngoko } \\
\text { (3) Ragam Madya } \\
\text { (4) Ragam Krama } \\
\text { (5) Ragam Paseban } \\
\text { a. Basa Bagongan } \\
\quad \text { b. Basa Kedhaton } \\
\text { (6) Ragam Rengga Basa (Indah) }\end{array}$ \\
\hline
\end{tabular}

\section{E. PENUTUP}

Secara fungsional kemasyarakatan yang baku pemakaian bahasa Jawa umumnya menggunakan tiga ragam, yaitu ragam ngoko, madya, dan krama. Sekalipun demikian diakui bahwa pemakaian bahasa Jawa tidak sekedar dalam konteks cakapan pragmatis sehari-hari. Dalam faktanya bahasa Jawa dipakai dalam segmen kewilayahan yang lebih luas, termasuk di bidang kesenian wayang purwa yang menggambarkan kompleksitas kehidupan masyarakat Jawa yang lebih utuh dan komprehensif.

\section{DAFTAR PUSTAKA}

Adisumarto, Mukidi. 1991. "Unggah-Ungguh Bahasa Jawa Modern”, Makalah Seminar Pada Seminar Tatakrama dan Unggah-Ungguh dalam Kebudayaan Jawa, Juni 1991. Yogyakarta: Javanologi.

Antunsuhono. 1953. Reringkesaning Paramasastra Djawi. Kangge Sekolah Guru B, Lsp. Jogjakarta: Penerbitan Soejadi.

Basir, Udjang Pr. M. 2002. Sosiolinguistik, Pengantar Kajian Tindak Berbahasa. Surabaya: Penerbit UNESA University Press Anggota IKAPI.

Depdikbud. 1946. Karti Basa. Djakarta: Kementrian Pengajaran Pendidikan dan Keboedajaan.

Fishman, Joshua A. 1972. The Sociology of Language. Rowley-Massachussetts: New Bury House Publishers.
Hadiwidjono, RDS. 1967. Tata Sastra. Jogjakarta: Pertjetakan U.P. Indonesia.

Padmosoekotjo, S. 1960. Ngengrengan Kasusastran Djawa I-II. Jogjakarta: Penerbit dan Toko Buku Hien Hoo Sing.

Poedjosoedarmo, Soepomo. 1979. Tingkat Tutur Bahasa Jawa. Jakarta: Pusat Pembinaan dan Pengembangan Bahasa Departemen Pendidikan dan Kebudayaan.

Poerwadarminta, W.J.S. 1953. Sarining Paramasastra Djawa. Djakarta: Weton Noordhoff-Kolff, N.V. Kebon Sirih 46.

Purwadi, dkk. 2005. Tata Bahasa Jawa. Yogyakarta: Penerbit Media Abadi.

Sastroamidjojo, Seno. 1964. Renungan tentang Pertundjukan Wajang Kulit. Djakarta: Penerbit Kinta Djakarta.

Soetrisno, R. 2004. Nilai Filosofis Kidungan Pakeliran. Yogyakarta: Penerbit Adita Pressindoesti Yogyakarta.

S. Padmosoekotjo. 1958. Ngengrengan Kasusastran Djawa I-II, Kangge Para Siswa Sekolah Guru lan Sekolah Landjutan Lijane. Jogjakarta: Hien Hoo Sing.

Yuwana, Setya. 2000. Pergelaran Wayang Krucil di Desa Janjang, Kecamatan Jiken, Kabupaten Blora Era 1990-An, Kajian Hegemoni Negara di Tingkat Lokal Melalui Kesenian Rakyat. Disertasi Program Pascasarjana Universitas Airlangga Surabaya. 